\title{
Fixed point results for generalized $\Theta$-contractions
}

\author{
Jamshaid Ahmad ${ }^{\mathrm{a}}$, Abdullah E. Al-Mazrooei ${ }^{\mathrm{a}}$, Yeol Je Cho ${ }^{\mathrm{b}, \mathrm{c}, *}$, Young-Oh Yang $^{\mathrm{d}, *}$ \\ ${ }^{a}$ Department of Mathematics, University of Jeddah, P. O. Box 80327, Jeddah 21589, Saudi Arabia. \\ ${ }^{b}$ Department of Mathematics Education and the RINS, Gyeongsang National University, Jinju 660-701, Korea. \\ ${ }^{c}$ Center for General Education, China Medical University, Taichung 40402, Taiwan. \\ ${ }^{d}$ Department of Mathematics, Jeju National University, Jeju 690-756, Korea.
}

Communicated by P. Kumam

\begin{abstract}
The aim of this paper is to extend the result of [M. Jleli, B. Samet, J. Inequal. Appl., 2014 (2014), 8 pages] by applying a simple condition on the function $\Theta$. With this condition, we also prove some fixed point theorems for Suzuki-Berinde type $\Theta$-contractions which generalize various results of literature. Finally, we give one example to illustrate the main results in this paper. (C) 2017 All rights reserved.
\end{abstract}

Keywords: Complete metric space, $\Theta$-contraction, Suzuki-Berinde type $\Theta$-contraction, fixed point. 2010 MSC: 46S40, 47H10, 54H25.

\section{Introduction and preliminaries}

Banach's contraction principle [4] is one of the pivotal results of nonlinear analysis and its applications, which establishes that, if $F$ is a mapping from a complete metric space $(X, d)$ into itself and there exists a constant $k \in[0,1)$ such that

$$
d(F x, F y) \leqslant k d(x, y)
$$

for all $x, y \in X$, then $F$ has a unique fixed point in $X$.

Due to its importance and simplicity, many authors have obtained a lot of interesting extensions and generalizations of Banach's contraction principle (see $[1-3,6,10,12]$ and references therein).

Especially, in 1962, Edelstein [7] established the following version of Banach's contraction principle for a compact metric space.

Theorem 1.1. Let $(\mathrm{X}, \mathrm{d})$ be a compact metric space and $\mathrm{F}: \mathrm{X} \rightarrow \mathrm{X}$ be a self-mapping. Assume that

$$
d(F x, F y)<d(x, y)
$$

holds for all $\mathrm{x}, \mathrm{y} \in \mathrm{X}$ with $\mathrm{x} \neq \mathrm{y}$. Then $\mathrm{F}$ has a unique fixed point in $\mathrm{X}$.

\footnotetext{
${ }^{*}$ Corresponding author

Email addresses: jamshaid_jasim@yahoo.com (Jamshaid Ahmad), aealmazrooei@uj.edu.sa (Abdullah E. Al-Mazrooei), yjcho@gnu.ac.kr (Yeol Je Cho), yangyo@jejunu.ac.kr (Young-Oh Yang)

doi:10.22436/jnsa.010.05.07
}

Received 2017-01-14 
In 2008, Suzuki [11] proved generalized versions of Edelstein's results in a compact metric space as follows:

Theorem 1.2. Let $(\mathrm{X}, \mathrm{d})$ be a compact metric space and $\mathrm{F}: \mathrm{X} \rightarrow \mathrm{X}$ be a self-mapping. Assume that

$$
\frac{1}{2} \mathrm{~d}(x, F x)<\mathrm{d}(x, y) \Longrightarrow \mathrm{d}(F x, F y)<d(x, y)
$$

holds for all $x, y \in X$ with $x \neq y$. Then $F$ has a unique fixed point in $X$.

On the other hand, Berinde [5] gave the following well-known result as a generalization of Banach's contraction principle:

Theorem 1.3. Let $(\mathrm{X}, \mathrm{d})$ be a complete metric space and $\mathrm{F}: \mathrm{X} \rightarrow \mathrm{X}$ be a self-mapping. If there exist a constant $\mathrm{k} \in[0,1)$ and a constant $\mathrm{L} \geqslant 0$ such that

$$
d(F x, F y) \leqslant k d(x, y)+\operatorname{Lmin}\{d(x, F x), d(y, F y), d(x, F y), d(y, F x)\},
$$

for all $x, y \in X$, then $F$ has a unique fixed point in $X$.

Recently, Jleli and Samet [9] introduced a new type of contraction which is called the $\Theta$-contraction and established some new fixed point theorems for such a contraction in the context of generalized metric spaces.

\section{Definition 1.4.}

(1) Let $\Theta:(0, \infty) \rightarrow(1, \infty)$ be a function satisfying the following conditions:

$\left(\Theta_{1}\right) \Theta$ is nondecreasing;

$\left(\Theta_{2}\right)$ for each sequence $\left\{\alpha_{n}\right\} \subseteq \mathbb{R}^{+}$,

$$
\lim _{n \rightarrow \infty} \Theta\left(\alpha_{n}\right)=1 \Longleftrightarrow \lim _{n \rightarrow \infty} \alpha_{n}=0 ;
$$

$\left(\Theta_{3}\right)$ there exist $0<k<1$ and $l \in(0, \infty]$ such that $\lim _{\alpha \rightarrow 0^{+}} \frac{\Theta(\alpha)-1}{\alpha^{k}}=l$.

(2) A mapping $F: X \rightarrow X$ is called the $\Theta$-contraction if there exists the function $\Theta$ satisfying $\left(\Theta_{1}\right)-\left(\Theta_{3}\right)$ and a constant $k \in(0,1)$ such that, for all $x, y \in X$,

$$
d(F x, F y) \neq 0 \Longrightarrow \Theta(d(F x, F y)) \leqslant[\Theta(d(x, y))]^{k} .
$$

Theorem 1.5 ([9]). Let $(\mathrm{X}, \mathrm{d})$ be a complete metric space and $\mathrm{F}: \mathrm{X} \rightarrow \mathrm{X}$ be a $\Theta$-contraction. Then $\mathrm{F}$ has a unique fixed point.

Also, they showed that any Banach contraction is a particular case of $\Theta$-contraction while there exist $\Theta$-contractions which are not Banach contractions.

To be consistent with Jleli and Samet [9], we denote by $\Psi$ the set of all functions $\Theta:(0, \infty) \rightarrow(1, \infty)$ satisfying the above conditions $\left(\Theta_{1}\right)-\left(\Theta_{3}\right)$.

In 2015, Hussain et al. [8] modified and extended the above result and proved the following fixed point theorem for a generalized $\Theta$-contractive condition in the setting of complete metric spaces:

Theorem 1.6. Let $(X, d)$ be a complete metric space and $\mathrm{F}: \mathrm{X} \rightarrow \mathrm{X}$ be a self-mapping. If there exists a function $\Theta \in \Omega$ and positive real numbers $\alpha, \beta, \gamma, \delta$ with $0 \leqslant \alpha+\beta+\gamma+2 \delta<1$ such that

$$
\Theta(d(F x, F y)) \leqslant[\Theta(d(x, y))]^{\alpha} \cdot[\Theta(d(x, F x))]^{\beta} \cdot[\Theta(d(y, F y))]^{\gamma} \cdot\left[\Theta((d(x, F y)+d(y, F x))]^{\delta},\right.
$$

for all $x, y \in X$, then $\mathrm{F}$ has a unique fixed point.

In this paper, we use the following condition instead of the condition $\left(\Theta_{3}\right)$ in Definition 1.4. 
$\left(\Theta_{3}^{\prime}\right) \Theta$ is continuous on $(0, \infty)$.

We denote by $\Omega$ the set of all functions satisfying the conditions $\left(\Theta_{1}\right),\left(\Theta_{2}\right)$, and $\left(\Theta_{3}^{\prime}\right)$.

Example 1.7. Define some functions as follows: for all $t>0$,

(1) $\Theta_{1}(t)=e^{\sqrt{t}}$

(2) $\Theta_{2}(t)=e^{\sqrt{t e^{t}}}$;

(3) $\Theta_{3}(t)=e^{t}$;

(4) $\Theta_{4}(t)=\cosh t$;

(5) $\Theta_{5}(t)=1+\ln (1+t)$;

(6) $\Theta_{6}(t)=e^{t e^{t}}$.

Then $\Theta_{1}, \Theta_{2}, \Theta_{3}, \Theta_{4}, \Theta_{5}, \Theta_{6} \in \Omega$.

Example 1.8. Note that the conditions $\Theta_{3}$ and $\Theta_{3}^{\prime}$ are independent of each other. Indeed, for $p \geqslant 1$, $\Theta(t)=e^{t^{p}}$ satisfies the conditions $\left(\Theta_{1}\right)$ and $\left(\Theta_{2}\right)$, but it does not satisfy $\left(\Theta_{3}\right)$, while it satisfies the condition $\left(\Theta_{3}^{\prime}\right)$. Therefore, $\Omega \nsubseteq \Psi$. Again, for any $p>1$ and $m \in\left(0, \frac{1}{p}\right)$, a function $\Theta(t)=1+t^{m}(1+[t])$, where [t] denotes the integer part of $t$, satisfies the conditions $\left(\Theta_{1}\right)$ and $\left(\Theta_{2}\right)$, but it does not satisfy $\left(\Theta_{3}^{\prime}\right)$, while it satisfies the condition $\left(\Theta_{3}\right)$ for any $k \in\left(\frac{1}{p}, 1\right)$. Therefore, $\Psi \nsubseteq \Omega$. Also, if we define $\Theta(t)=e^{\sqrt{t}}$, then $\Theta \in \Psi$ and $\Theta \in \Omega$. Therefore, $\Psi \cap \Omega \neq \emptyset$.

\section{Main results}

In this section, we define the $\Theta$-contraction for a new family of functions $\Omega$ and establish some fixed point theorems in the context of complete metric spaces.

Definition 2.1. Let $(X, d)$ be a metric space and $F$ be a self-mapping on $X$. We say that $F$ is the $\Theta$-contraction if there exist $\Theta \in \Omega$ and a constant $k \in(0,1)$ such that

$$
\Theta(d(F x, F y)) \leqslant[\Theta(d(x, y))]^{k},
$$

for all $x, y \in X$ with $F x \neq F y$.

In view of Example 1.8, it is meaningful to consider the result of Jleli and Samet [9] with the function $\Theta \in \Omega$ instead of $\Theta \in \Psi$.

Theorem 2.2. Let $(\mathrm{X}, \mathrm{d})$ be a complete metric space and $\mathrm{F}: \mathrm{X} \rightarrow \mathrm{X}$ be the $\Theta$-contraction. Then $\mathrm{F}$ has a unique fixed point $z \in X$ and, for any $x_{0} \in X$, the sequence $\left\{\mathrm{F}^{n} x_{0}\right\}$ converges to the point $z$.

Proof. Let $x_{0} \in X$, we define a sequence $\left\{x_{n}\right\}$ by $x_{n+1}=F^{n} x_{0}=F x_{n}$ for each $n \in \mathbb{N}$. If there exists $n_{0} \in \mathbb{N}$ such that $x_{n_{0}}=x_{n_{0}+1}$, then $x_{n_{0}}$ is a fixed point of $F$ and we have nothing to prove. So, without loss of generality, we assume that $x_{n} \neq x_{n+1}$, i.e., $F x_{n-1} \neq F x_{n}$ for all $n \in \mathbb{N}$. It follows from the assumption that

$$
\begin{aligned}
1<\Theta\left(d\left(x_{n}, x_{n+1}\right)\right)=\Theta\left(d\left(F x_{n-1}, F x_{n}\right)\right) & \leqslant\left[\Theta\left(d\left(x_{n-1}, x_{n}\right)\right)\right]^{k}=\left[\Theta\left(d\left(F x_{n-2}, F x_{n-1}\right)\right)\right]^{k} \\
& \leqslant\left[\Theta\left(d\left(x_{n-2}, x_{n-1}\right)\right)\right]^{k^{2}} \\
& \vdots \\
& \leqslant\left[\Theta\left(d\left(x_{0}, x_{1}\right)\right)\right]^{k^{n}}
\end{aligned}
$$

for all $n \in \mathbb{N}$. Since $\Theta \in \Omega$, by taking the limit as $n \rightarrow \infty$ in (2.1), we have

$$
\lim _{n \rightarrow \infty} \Theta\left(d\left(x_{n}, x_{n+1}\right)\right)=1 \Longleftrightarrow \lim _{n \rightarrow \infty} d\left(x_{n}, x_{n+1}\right)=0 .
$$


Now, we claim that $\left\{x_{n}\right\}$ is a Cauchy sequence. Suppose that $\left\{x_{n}\right\}$ is not a Cauchy sequence. Then there exists $\varepsilon>0$ and the sequences $\{p(n)\}$ and $\{q(n)\}$ of natural numbers such that, for any $p(n)>q(n)>n$,

$$
d\left(x_{p(n)}, x_{q(n)}\right) \geqslant \varepsilon, \quad d\left(x_{p(n)-1}, x_{q(n)}\right)<\varepsilon,
$$

for each $n \in \mathbb{N}$. So, by the triangle inequality and (2.3), we have

$$
\varepsilon \leqslant d\left(x_{p(n)}, x_{q(n)}\right) \leqslant d\left(x_{p(n)}, x_{p(n)-1}\right)+d\left(x_{p(n)-1}, x_{q(n)}\right)<d\left(x_{p}(n)-1, x_{p}(n)\right)+\varepsilon .
$$

By taking the limit as $n \rightarrow \infty$ in (2.4), we have

$$
\lim _{n \rightarrow \infty} d\left(x_{p(n)}, x_{q(n)}\right)=\varepsilon
$$

From (2.2), we can choose a natural number $n_{0} \in \mathbb{N}$ such that

$$
\mathrm{d}\left(\mathrm{x}_{\mathrm{p}(\mathrm{n})}, \mathrm{x}_{\mathrm{p}(\mathrm{n})+1}\right)<\frac{\varepsilon}{4}, \quad \mathrm{~d}\left(\mathrm{x}_{\mathbf{q}(\mathrm{n})}, \mathrm{x}_{\mathbf{q}(\mathrm{n})+1}\right)<\frac{\varepsilon}{4},
$$

for each $n \geqslant n_{0}$.

Next, we claim that $F x_{p(n)} \neq F x_{q(n)}$ for all $n \geqslant n_{0}$, that is,

$$
d\left(x_{p(n)+1}, x_{q(n)+1}\right)=d\left(F x_{p(n)}, F x_{q(n)}\right)>0 .
$$

Suppose that there exists $n \geqslant n_{0}$ such that $d\left(x_{p(n)+1}, x_{q(n)+1}\right)=0$. It follows from (2.2), (2.5), and (2.6) that

$$
\begin{aligned}
\varepsilon & \leqslant d\left(x_{p(n)}, x_{q(n)}\right) \leqslant d\left(x_{p(n)}, x_{p(n)+1}\right)+d\left(x_{p(n)+1}, x_{q(n)+1}\right)+d\left(x_{q(n)+1}, x_{q(n)}\right) \\
& <\frac{\varepsilon}{4}+0+\frac{\varepsilon}{4} \\
& =\frac{\varepsilon}{2}
\end{aligned}
$$

which is a contradiction. Thus the relation (2.7) holds. Then, by the assumption, we have

$$
\Theta\left(d\left(F x_{p(n)}, F x_{q(n)}\right)\right) \leqslant\left[\Theta\left(d\left(x_{p(n)}, x_{q(n)}\right)\right)\right]^{k} .
$$

By taking the limit as $n \rightarrow \infty$ and using $\left(\Theta_{3}^{\prime}\right)$ and (2.5), it follows that

$$
\Theta(\varepsilon) \leqslant[\Theta(\varepsilon)]^{k},
$$

which is a contradiction. Thus $\left\{x_{n}\right\}$ is a Cauchy sequence. The completeness of $X$ ensures that there exists $z \in X$ such that $x_{n} \rightarrow z$ as $n \rightarrow \infty$.

Finally, the continuity of $\mathrm{F}$ yields

$$
d(z, F z)=\lim _{n \rightarrow \infty} d\left(x_{n}, F x_{n}\right)=\lim _{n \rightarrow \infty} d\left(x_{n}, x_{n+1}\right)=d(z, z)=0 .
$$

Hence $z$ is a fixed point of $F$.

Now, we show the uniqueness of the fixed point $z$. Suppose that there exists another fixed point $u$ of F distinct from $z$, that is,

$$
\mathrm{F} z=z \neq u=F u \text {. }
$$

Then it follows from the assumption that

$$
\Theta(d(z, u))=\Theta(d(F z, F u)) \leqslant[\Theta(d(z, u))]^{k},
$$

which is a contradiction since $k \in(0,1)$. Thus $z$ is the unique fixed point of $F$. This completes the proof.

Note that the family $\Omega$ consists of a large class of functions. For example, if we take

$$
\Theta(t)=2-\frac{2}{\pi} \arctan \left(\frac{1}{t^{a}}\right),
$$

where $0<a<1$ and $t>0$, then $\Theta \in \Omega$ and we can obtain the following result from Theorem 2.2. 
Theorem 2.3. Let $(\mathrm{X}, \mathrm{d})$ be a complete metric space and $\mathrm{F}$ be a self-mapping on $\mathrm{X}$. If there exist constants $\mathrm{a}, \mathrm{k} \in$ $[0,1)$ such that

$$
2-\frac{2}{\pi} \arctan \left(\frac{1}{d(F x, F y)^{a}}\right) \leqslant\left[2-\frac{2}{\pi} \arctan \left(\frac{1}{d(x, y)^{a}}\right)\right]^{k},
$$

for all $\mathrm{x}, \mathrm{y} \in \mathrm{X}$ with $\mathrm{Fx} \neq \mathrm{Fy}$, then $\mathrm{F}$ has a unique fixed point $z \in \mathrm{X}$ and, for all $\mathrm{x}_{0} \in \mathrm{X}$, the sequence $\left\{\mathrm{F}^{\mathrm{n}} \mathrm{x}_{0}\right\}$ converges to the point $z$.

\section{Fixed point results for the Suzuki-Berinde type $\Theta$-contraction}

In the present section, we define the Suzuki-Berinde type $\Theta$-contraction to prove some fixed point theorems in the context of complete metric spaces.

Definition 3.1. Let $(X, d)$ be a metric space and $F$ be a self-mapping on $X$. We say that $F$ is the SuzukiBerinde type $\Theta$-contraction if there exist $\Theta \in \Omega, k \in(0,1)$ and $L \geqslant 0$ such that, for all $x, y \in X$ with $\mathrm{Fx} \neq \mathrm{Fy}$,

$$
\frac{1}{2} d(x, F x)<d(x, y) \Longrightarrow \Theta(d(F x, F y)) \leqslant[\Theta(d(x, y))]^{k}+\operatorname{Lmin}\{d(x, F x), d(x, F y), d(y, F x)\} .
$$

Theorem 3.2. Let $(\mathrm{X}, \mathrm{d})$ be a complete metric space and $\mathrm{F}: \mathrm{X} \rightarrow \mathrm{X}$ be a self-mapping satisfying the Suzuki-Berinde type $\Theta$-contraction. Then $\mathrm{F}$ has a unique fixed point $z \in X$ and, for any $x_{0} \in X$, the sequence $\left\{\mathrm{F}^{\mathrm{n}} \mathrm{x}_{0}\right\}$ converges to the point $z$.

Proof. For any $x_{0} \in X$, we define the sequence $\left\{x_{n}\right\}$ by $x_{n+1}=F^{n} x_{0}=F x_{n}$ for each $n \in \mathbb{N}$. If there exists $n_{0} \in \mathbb{N}$ such that $x_{n_{0}}=x_{n_{0}+1}$, then $x_{n_{0}}$ is a fixed point of $F$ and we have nothing to prove. So we assume that $x_{n-1} \neq x_{n}$ or

$$
0<d\left(x_{n-1}, F x_{n-1}\right)
$$

for each $n \in \mathbb{N}$. Therefore, we have

$$
\frac{1}{2} d\left(x_{n-1}, F x_{n-1}\right)<d\left(x_{n-1}, F x_{n-1}\right)=d\left(x_{n-1}, x_{n}\right),
$$

for each $n \in \mathbb{N}$. It follows from the assumption that

$$
\Theta\left(d\left(F x_{n-1}, F x_{n}\right)\right) \leqslant\left[\Theta\left(d\left(x_{n-1}, x_{n}\right)\right)\right]^{k}+\operatorname{Lin}\left\{d\left(x_{n-1}, F x_{n-1}\right), d\left(x_{n-1}, F x_{n}\right), d\left(x_{n}, F x_{n-1}\right)\right\},
$$

which implies that

$\Theta\left(d\left(F x_{n-1}, F x_{n}\right)\right) \leqslant\left[\Theta\left(d\left(x_{n-1}, x_{n}\right)\right)\right]^{k}+\operatorname{Lmin}\left\{d\left(x_{n-1}, x_{n}\right), d\left(x_{n-1}, x_{n+1}\right), d\left(x_{n}, x_{n}\right)\right\}=\left[\Theta\left(d\left(x_{n-1}, x_{n}\right)\right)\right]^{k}$.

Therefore, we have

$$
1<\Theta\left(d\left(x_{n}, x_{n+1}\right)\right)=\Theta\left(d\left(F x_{n-1}, F x_{n}\right)\right) \leqslant\left[\Theta\left(d\left(x_{n-1}, x_{n}\right)\right)\right]^{k} \leqslant \cdots \leqslant\left[\Theta\left(d\left(x_{0}, x_{1}\right)\right)\right]^{k^{n}},
$$

for each $n \in \mathbb{N}$. Since $\Theta \in \Omega$, by taking the limit as $n \rightarrow \infty$ in (3.2), we have

$$
\lim _{n \rightarrow \infty} \Theta\left(d\left(x_{n}, x_{n+1}\right)\right)=1 \Longleftrightarrow \lim _{n \rightarrow \infty} d\left(x_{n}, x_{n+1}\right)=0 .
$$

Now, we claim that $\left\{x_{n}\right\}$ is a Cauchy sequence. Suppose that $\left\{x_{n}\right\}$ is not a Cauchy sequence. Then there exists $\varepsilon>0$ and the sequences $\{p(n)\}$ and $\{q(n)\}$ of natural numbers such that, for any $p(n)>q(n)>n$,

$$
d\left(x_{p(n)}, x_{q(n)}\right) \geqslant \varepsilon, \quad d\left(x_{p(n)-1}, x_{q(n)}\right)<\varepsilon,
$$


for each $n \in \mathbb{N}$. So, by the triangle inequality and (3.4), we have

$$
\varepsilon \leqslant d\left(x_{p(n)}, x_{q(n)}\right) \leqslant d\left(x_{p(n)}, x_{p(n)-1}\right)+d\left(x_{p(n)-1}, x_{q(n)}\right)<d\left(x_{p(n)-1}, F x_{p(n)-1}\right)+\varepsilon .
$$

By taking the limit as $n \rightarrow \infty$ in (3.5) and using the inequality (3.3), we have

$$
\lim _{n \rightarrow \infty} d\left(x_{p(n)}, x_{q(n)}\right)=\varepsilon .
$$

From (3.1) and (3.4), we can choose a natural number $n_{0} \in \mathbb{N}$ such that

$$
\frac{1}{2} d\left(x_{p(n)}, F x_{p(n)}\right)<\frac{\varepsilon}{2}<d\left(x_{p(n)}, x_{q(n)}\right),
$$

for all $n \geqslant n_{0}$. On the other hand, by the assumption, we have

$$
\begin{aligned}
\Theta\left(d\left(F x_{p(n)}, F x_{q(n)}\right)\right) \leqslant & {\left[\Theta\left(d\left(x_{p(n)}, x_{q(n)}\right)\right)\right]^{k} } \\
& +L \min \left\{d\left(x_{p(n)}, F x_{p(n)}\right), d\left(x_{p(n)}, F x_{q(n)}\right), d\left(x_{q(n)}, F x_{p(n)}\right)\right\} \\
= & {\left[\Theta\left(d\left(x_{p(n)}, x_{q(n)}\right)\right)\right]^{k} } \\
& +\operatorname{Lmin}\left\{d\left(x_{p(n)}, x_{p(n)+1}\right), d\left(x_{p(n)}, x_{q(n)+1}\right), d\left(x_{q(n)}, x_{p(n)+1}\right)\right\} .
\end{aligned}
$$

By taking the limit as $n \rightarrow \infty$ in (3.7) and using $\left(\Theta_{3}^{\prime}\right)$ and (3.6), we have

$$
\Theta(\varepsilon) \leqslant[\Theta(\varepsilon)]^{k},
$$

which is a contradiction since $k \in(0,1)$. Thus $\left\{x_{n}\right\}$ is a Cauchy sequence. Thus the completeness of $X$ ensures that there exists $z \in X$ such that $x_{n} \rightarrow z$ as $n \rightarrow \infty$, that is,

$$
\lim _{n \rightarrow \infty} d\left(x_{n}, z\right)=0 .
$$

Next, we claim that

$$
\frac{1}{2} \mathrm{~d}\left(x_{n}, F x_{n}\right)<d\left(x_{n}, z\right) \text { or } \frac{1}{2} d\left(F x_{n}, F^{2} x_{n}\right)<d\left(F x_{n}, z\right),
$$

for each $n \in \mathbb{N}$. Suppose that there exists $m \in \mathbb{N}$ such that

$$
\frac{1}{2} d\left(x_{m}, F x_{m}\right) \geqslant d\left(x_{m}, z\right) \text { and } \frac{1}{2} d\left(F x_{m}, F^{2} x_{m}\right) \geqslant d\left(F x_{m}, z\right) .
$$

Then we have

$$
2 d\left(x_{m}, z\right) \leqslant d\left(x_{m}, F x_{m}\right) \leqslant d\left(x_{m}, z\right)+d\left(z, F x_{m}\right),
$$

which implies that

$$
d\left(x_{m}, z\right) \leqslant d\left(z, F x_{m}\right)
$$

It follows from (3.9) and (3.10) that

$$
d\left(x_{m}, z\right) \leqslant d\left(z, F x_{m}\right) \leqslant \frac{1}{2} d\left(F x_{m}, F^{2} x_{m}\right) .
$$

Since $\frac{1}{2} d\left(x_{m}, F x_{m}\right)<d\left(x_{m}, F x_{m}\right)$, by the assumption, we have

$$
\Theta\left(d\left(F x_{m}, F^{2} x_{m}\right)\right) \leqslant\left[\Theta\left(d\left(x_{m}, F x_{m}\right)\right)\right]^{k}+\operatorname{Lmin}\left\{d\left(x_{m}, F x_{m}\right), d\left(x_{m}, F^{2} x_{m}\right), d\left(F x_{m}, F x_{m}\right)\right\},
$$


which implies that

$$
\Theta\left(d\left(F x_{m}, F^{2} x_{m}\right)\right) \leqslant\left[\Theta\left(d\left(x_{m}, F x_{m}\right)\right)\right]^{k} .
$$

Since $\Theta$ is strictly increasing, we have

$$
d\left(F x_{m}, F^{2} x_{m}\right)<d\left(x_{m}, F x_{m}\right) .
$$

It follows from (3.9), (3.10), and (3.11) that

$$
d\left(F x_{m}, F^{2} x_{m}\right)<d\left(x_{m}, F x_{m}\right) \leqslant d\left(x_{m}, z\right)+d\left(z, F x_{m}\right) \leqslant \frac{1}{2} d\left(F x_{m}, F^{2} x_{m}\right)+\frac{1}{2} d\left(F x_{m}, F^{2} x_{m}\right)=d\left(F x_{m}, F^{2} x_{m}\right),
$$

which is a contradiction. Hence (3.8) holds and so, for each $n \in \mathbb{N}$,

$$
1<\Theta\left(d\left(F x_{n}, F z\right)\right) \leqslant\left[\Theta\left(d\left(x_{n}, z\right)\right)\right]^{k}+\operatorname{Lmin}\left\{d\left(x_{n}, F x_{n}\right), d\left(x_{n}, F z\right), d\left(z, F x_{n}\right)\right\},
$$

which implies that

$$
1<\Theta\left(d\left(F x_{n}, F z\right)\right) \leqslant\left[\Theta\left(d\left(x_{n}, z\right)\right)\right]^{k}+\operatorname{Lmin}\left\{d\left(x_{n}, x_{n+1}\right), d\left(x_{n}, F z\right), d\left(z, x_{n+1}\right)\right\} .
$$

Using (3.12) and $\left(\Theta_{2}\right)$, we have

$$
\lim _{n \rightarrow \infty} \Theta\left(d\left(F x_{n}, F z\right)\right)=1
$$

and so, from $\left(\Theta_{2}\right)$,

$$
\lim _{n \rightarrow \infty} d\left(F x_{n}, F z\right)=0
$$

Therefore, we have

$$
d(z, F z)=\lim _{n \rightarrow \infty} d\left(x_{n+1}, F z\right)=\lim _{n \rightarrow \infty} d\left(F x_{n}, F z\right)=0 .
$$

Hence $z$ is a fixed point of $F$.

Now, we show the uniqueness of the fixed point $z$. Suppose that there exists another fixed point $u$ of F distinct from $z$, that is,

$$
\mathrm{F} z=z \neq \mathrm{u}=\mathrm{Fu} \text {. }
$$

Thus we have $\frac{1}{2} \mathrm{~d}(z, F z)<\mathrm{d}(z, \mathrm{u})$ and so, from the assumption,

$$
\Theta(d(z, u))=\Theta(d(F z, F u)) \leqslant[\Theta(d(z, u))]^{k}+\operatorname{Lmin}\{d(z, F z), d(z, F u), d(u, F z)\},
$$

which implies that

$$
\Theta(d(z, u)) \leqslant[\Theta(d(z, u))]^{k},
$$

which is a contradiction since $k \in(0,1)$. Thus $z$ is the unique fixed point of $F$. This completes the proof.

Theorem 3.3. Let $(\mathrm{X}, \mathrm{d})$ be a complete metric space and $\mathrm{F}: \mathrm{X} \rightarrow \mathrm{X}$ be a self-mapping. If there exists $\Theta \in \Omega$ such that, for all $\mathrm{x}, \mathrm{y} \in \mathrm{X}$ with $\mathrm{Fx} \neq \mathrm{Fy}$,

$$
\frac{1}{2} d(x, F x)<d(x, y) \Longrightarrow \Theta(d(F x, F y)) \leqslant[\Theta(d(x, y))]^{k},
$$

then $\mathrm{F}$ has a unique fixed point $z \in \mathrm{X}$ and, for any $\mathrm{x}_{0} \in \mathrm{X}$, the sequence $\left\{\mathrm{F}^{\mathrm{n}} \mathrm{x}_{0}\right\}$ is convergent to the point $z$.

Theorem 3.4. Let $(\mathrm{X}, \mathrm{d})$ be a complete metric space and $\mathrm{F}$ be a self-mapping on $\mathrm{X}$. If there exist constants $\mathrm{a}, \mathrm{k} \in$ $(0,1)$ and $\mathrm{L} \geqslant 0$ such that

$$
\begin{aligned}
\frac{1}{2} d(x, F x)<d(x, y) & \Longrightarrow 2-\frac{2}{\pi} \arctan \left(\frac{1}{d(F x, F y)^{a}}\right) \\
& \leqslant\left[2-\frac{2}{\pi} \arctan \left(\frac{1}{d(x, y)^{a}}\right)\right]^{k}+\operatorname{Linin}\{d(x, F x), d(x, F y), d(y, F x)\},
\end{aligned}
$$

for all $x, y \in X$ with $\mathrm{Fx} \neq \mathrm{Fy}$, then $\mathrm{F}$ has a unique fixed point $z \in \mathrm{X}$ and, for any $\mathrm{x}_{0} \in \mathrm{X}$, the sequence $\left\{\mathrm{F}^{\mathrm{n}} \mathrm{x}_{0}\right\}$ converges to the point $z$. 
Proof. Taking $\Theta(t)=2-\frac{2}{\pi} \arctan \left(\frac{1}{t^{a}}\right)$ in Theorem 3.2, we have the conclusion.

Corollary 3.5. Let $(\mathrm{X}, \mathrm{d})$ be a complete metric space and $\mathrm{F}$ be a self-mapping on $\mathrm{X}$. If there exist constants $\mathrm{a}, \mathrm{k} \in$ $(0,1)$ such that

$$
\frac{1}{2} \mathrm{~d}(x, F x)<\mathrm{d}(x, y) \Longrightarrow 2-\frac{2}{\pi} \arctan \left(\frac{1}{d(F x, F y)^{a}}\right) \leqslant\left[2-\frac{2}{\pi} \arctan \left(\frac{1}{d(x, y)^{a}}\right)\right]^{k},
$$

for all $x, y \in X$ with $\mathrm{Fx} \neq \mathrm{Fy}$, then $\mathrm{F}$ has a unique fixed point $z \in X$ and, for any $\mathrm{x}_{0} \in \mathrm{X}$, the sequence $\left\{\mathrm{F}^{\mathrm{n}} \mathrm{x}_{0}\right\}$ converges to the point $z$.

Proof. Taking $\Theta(t)=2-\frac{2}{\pi} \arctan \left(\frac{1}{t^{a}}\right)$ in Theorem 3.3, we have the conclusion.

Example 3.6. Consider the sequence $\left\{S_{n}\right\}$ defined as follows:

$$
\mathrm{S}_{1}=1, \quad \mathrm{~S}_{2}=1+5, \cdots,
$$

and

$$
\mathrm{S}_{\mathrm{n}}=1+5+9+\cdots+(4 \mathrm{n}-3)=\mathrm{n}(2 \mathrm{n}-1), \cdots .
$$

Let $X=\left\{S_{n}: n \in \mathbb{N}\right\}$ and $d(x, y)=|x-y|$ be the usual metric. Then $(X, d)$ is a complete metric space. Define a mapping $F: X \rightarrow X$ by

$$
\mathrm{F}\left(\mathrm{S}_{1}\right)=\mathrm{S}_{1}, \quad \mathrm{~F}\left(\mathrm{~S}_{\mathrm{n}}\right)=\mathrm{S}_{\mathrm{n}-1},
$$

for each $n>1$. Clearly, $F$ does not satisfy Banach's contraction. In fact, we can easily check the following:

$$
\lim _{n \rightarrow \infty} \frac{d\left(F\left(S_{n}\right), F\left(S_{1}\right)\right)}{d\left(S_{n}, S_{1}\right)}=\lim _{n \rightarrow \infty} \frac{S_{n-1}-1}{S_{n}-1}=\lim _{n \rightarrow \infty} \frac{(n-1)(2 n-3)-1}{n(2 n-1)-1}=1 .
$$

Also, $\mathrm{F}$ does not satisfy the Suzuki-Berinde contraction. On the other hand, by considering the mapping $\Theta:(0, \infty) \rightarrow(1, \infty)$ defined by

$$
\Theta(t)=e^{t e^{t}}
$$

we can easily show that $\Theta \in \Omega$ and $F$ is the Suzuki-Berinde type $\Theta$-contraction, that is, there exist $k \in(0,1)$ and $L \geqslant 0$ such that

$$
\begin{aligned}
\frac{1}{2} \mathrm{~d}\left(S_{n}, F\left(S_{n}\right)\right)<d\left(S_{n}, S_{m}\right) & \Longrightarrow e^{d\left(F\left(S_{n}\right), F\left(S_{m}\right)\right) e^{d\left(F\left(S_{n}\right), F\left(S_{m}\right)\right)}} \\
& \leqslant e^{k d\left(S_{n}, S_{m}\right) e^{d\left(S_{n}, S_{m}\right)}}+\operatorname{Lmin}\left\{d\left(S_{n}, F\left(S_{n}\right)\right), d\left(S_{n}, F\left(S_{m}\right)\right), d\left(S_{m}, F\left(S_{n}\right)\right)\right\}
\end{aligned}
$$

Now, we consider the following two cases:

Case 1. For $1=n$ and $m>2$, we have

$$
e^{\left(2 m^{2}-5 m+3\right) e^{2 m^{2}-5 m+2}}<e^{k\left(2 m^{2}-m-1\right) e^{2 m^{2}-m-1}},
$$

for $k=e^{-1} \in(0,1)$ and so

$$
e^{d\left(F\left(S_{1}\right), F\left(S_{m}\right)\right) e^{d\left(F\left(S_{1}\right), F\left(S_{m}\right)\right)}} \leqslant e^{k d\left(S_{1}, S_{m}\right) e^{d\left(S_{1}, S_{m}\right)}}+\operatorname{Lin}\left\{d\left(S_{1}, F\left(S_{1}\right)\right), d\left(S_{1}, F\left(S_{m}\right)\right), d\left(S_{m}, F\left(S_{1}\right)\right)\right\},
$$

for some $L \geqslant 0$.

Case 2. For $m>n>1$, we have

$$
e^{\left(2 m^{2}-5 m-2 n^{2}+5 n\right) e^{2 m^{2}-5 m-2 n^{2}+5 n}}<e^{k\left(2 m^{2}-m-2 n^{2}+n\right) e^{2 m^{2}-m-2 n^{2}+n}},
$$

for $k=e^{-1} \in(0,1)$ and so

$$
e^{d\left(F\left(S_{n}\right), F\left(S_{m}\right)\right) e^{d\left(F\left(S_{n}\right), F\left(S_{m}\right)\right)}} \leqslant e^{k d\left(S_{n}, S_{m}\right) e^{d\left(S_{n}, S_{m}\right)}}+\operatorname{Lmin}\left\{d\left(S_{n}, F\left(S_{n}\right)\right), d\left(S_{n}, F\left(S_{m}\right)\right), d\left(S_{m}, F\left(S_{n}\right)\right)\right\},
$$

for some $L \geqslant 0$. Hence all of the conditions of Theorem 3.2 are satisfied and $S_{1}$ is a unique fixed point of the mapping F. But F does not satisfy the condition $\left(\Theta_{3}\right)$ and so the result [Theorem 5] of Jleli and Samet [9] and the result of Hussain et al. [8] can not be applied to this example. 


\section{References}

[1] A. Ahmad, A. S. Al-Rawashdeh, A. Azam, Fixed point results for $\{\alpha, \xi\}$-expansive locally contractive mappings, J. Inequal. Appl., 2014 (2014), 10 pages. 1

[2] J. Ahmad, A. Al-Rawashdeh, A. Azam, New fixed point theorems for generalized F-contractions in complete metric spaces, Fixed Point Theory Appl., 2015 (2015), 18 pages.

[3] A. Al-Rawashdeh, J. Ahmad, Common fixed point theorems for JS-contractions, Bull. Math. Anal. Appl., 8 (2016), 12-22. 1

[4] S. Banach, Sur les opérations dans les ensembles abstraits et leur application aux équations intégrales, Fund. Math., 3 (1922), 133-181. 1

[5] V. Berinde, General constructive fixed point theorems for Ćirić-type almost contractions in metric spaces, Carpathian J. Math., 24 (2008), 10-19. 1

[6] L. B. Ćirić, A generalization of Banach's contraction principle, Proc. Amer. Math. Soc., 45 (1974), 267-273. 1

[7] M. Edelstein, On fixed and periodic points under contractive mappings, J. London Math. Soc., 37 (1962), 74-79. 1

[8] N. Hussain, V. Parvaneh, B. Samet, C. Vetro, Some fixed point theorems for generalized contractive mappings in complete metric spaces, Fixed Point Theory Appl., 2015 (2015), 17 pages. 1, 3.6

[9] M. Jleli, B. Samet, A new generalization of the Banach contraction principle, J. Inequal. Appl., 2014 (2014), 8 pages. 1, $1.5,1,2,3.6$

[10] Z.-L. Li, S.-J. Jiang, Fixed point theorems of JS-quasi-contractions, Fixed Point Theory Appl., 2016 (2016), 11 pages. 1

[11] T. Suzuki, A new type of fixed point theorem in metric spaces, Nonlinear Anal., 71 (2009), 5313-5317. 1

[12] F. Vetro, A generalization of Nadler fixed point theorem, Carpathian J. Math., 31 (2015), 403-410. 1 